\title{
Uma proposta de framework teórico para a análise da experiência no jornalismo imersivo
}

\author{
Adalton dos Anjos Fonseca
}

Universidade Federal da Bahia, Salvador, Bahia, Brasil

Luciellen Lima

Universidade Federal da Bahia, Salvador, Bahia, Brasil

\section{Suzana Barbosa}

Universidade Federal da Bahia, Salvador, Bahia, Brasil

\section{Resumo}

Este artigo tem como objetivo propor um quadro teórico para a análise da experiência no jornalismo imersivo. Parte-se da discussão sobre a relação entre imersão e jornalismo e dos conceitos de experiência e jornalismo imersivo. A metodologia consiste na combinação da pesquisa bibliográfica com a análise de produtos. A proposta de quadro teórico está fundamentada em quatro níveis: epistêmico, estratégico, estilístico e estético - que se desdobram em aspectos teóricos e técnicos. Esses níveis mostraram uma inter-relação de experiências de agentes que compartilham suas emoções, repertórios, visões de mundo e vivências.

\section{Palavras-chave:}

Jornalismo imersivo. Experiência.

Imersão. Inovação no Jornalismo.

\section{Introdução}

Diferentes abordagens sobre a relação entre jornalismo e imersão têm sido realizadas pelos Estudos de Jornalismo. Na apuração, com técnicas como observação participante e etnografia jornalística; nas narrativas autorais mais extensas do jornalismo literário, na combinação de formatos narrativos como texto, áudio, vídeo ou infográficos para aprimorar a contextualização ou o jornalismo imersivo (CRAMER; MCDEVITT, 2004; DE LA PEÑA et al., 2010; DOMÍNGUEZ, 2013; HERMANN, 2016; MEDINA, 2003; SÁNCHEZ LAWS, 2017; SHIN; BIOCCA, 2017), a imersão está por trás de decisões e estratégias jornalísticas que permitem a reconstrução mental do acontecimento relatado com tanta precisão que dá a impressão de que estamos vivenciando-o.

Portanto, a imersão em narrativas jornalísticas pode acontecer em qualquer mídia 
e independe de recursos tecnológicos digitais. Por exemplo, muitas das características descritas pelo denominado jornalismo imersivo têm similaridades com a proposta do jornalismo literário. Martínez (2009) defende que ao contar uma história que une técnicas literárias com boas práticas jornalísticas, este repórter investe na imagem através da narrativa, ultrapassando camadas superficiais do real, indo a dimensões profundas e relatando de forma integral os sentidos e conexões de um acontecimento. A metáfora da imersão para a descrição do jornalismo literário aparece em Lima (2009) e Sims (2008). Ao descrever o novo jornalismo estadunidense, Wolfe (2005) explica que os repórteres e editores usavam recursos como "pontos de vista" e a criação de modo indireto de imagens para capturar a atenção pela via da intensidade e detalhamento de um acontecimento que despertava emoções nos leitores.

Porém, o jornalismo imersivo, conforme a abordagem aqui endereçada, se baseia numa ressignificação da imersão centrada na aproximação entre o público e os acontecimentos através de recursos tecnológicos digitais que interagem com as percepções sensoriais humanas (DOMÍNGUEZ, 2013). Surge num contexto no qual as organizações jornalísticas buscam um alinhamento com as possibilidades técnicas disponíveis e com os perfis de consumo emergentes, na tentativa de se manterem no mercado. Há anos as previsões para o jornalismo mostram um cenário de crise, tanto de credibilidade quanto econômica. Com a queda das receitas vindas da publicidade, o jornalismo digital ainda não conseguiu encontrar um modelo de negócio que garanta sua sustentação. Por conseguinte, as demissões atingem redações em todo o mundo (NEWMAN, 2018, 2019; WATSON, 2017).

Nesse cenário de incertezas, no contexto do quinto estágio de desenvolvimento para o jornalismo nas redes digitais (BARBOSA, 2013), e considerando o seu curso histórico ao longo dos últimos 25 anos (SALAVERRIA, 2019), o jornalismo imersivo aparece como estratégia de inovação de parte das organizações jornalísticas (WATSON, 2017). Formatos como a realidade virtual ( $\mathrm{RV})$, realidade aumentada (RA) e o newsgame concentram uma série de modificações do ponto de vista da apuração e produção de notícias, bem como na circulação e interação, cujo objetivo é colocar o usuário em uma posição de definir determinados rumos das narrativas. Através dos óculos de realidade virtual junto com o smartphone ou da própria tela do computador e movimentos com o mouse, é possível acessar um ambiente e o usuário pode escolher para onde voltar o olhar ao seu redor. Para autores como Alzamora e Tarcia (2012), o formato imersivo é inovador porque permite a emersão de um novo 
lugar para a informação jornalística. Para Hodgson (2017) e Temer e Santos (2016), a realidade virtual atrai o público jovem e seduz o usuário pela participação. Além disso, transformações na linguagem, nas formas de narrar e nas novas perspectivas de exploração também são vistas como potencialidades de inovação no jornalismo imersivo.

Nesse universo descrito, percebemos que há uma forte valorização do fator experiência ligado à imersão. Para o jornalismo, a ideia de experiência não é em si uma novidade. Independentemente do meio, ele sempre buscou aproximar o público da experiência do fato através de textos, fotos, sons e imagens dos acontecimento, porém, apesar de o jornalismo imersivo ser construído com material audiovisual, não é utilizado o verbo assistir para se referir ao consumo de produtos jornalísticos imersivos, como acontece com a televisão, por exemplo. O verbo utilizado em larga escala tanto pelo mercado quanto pela academia é experienciar. Esse destaque na ideia de experiência se deve ao avanço tecnológico que viabilizou a implementação de formatos que visam imergir o espectador na narrativa e não apenas apresentá-la, como acontece com as outras mídias (LONGHI; CAETANO, 2018).
O conceito de experiência emerge de modo direto ou indireto na prática jornalística. E, no caso do jornalismo imersivo, dá forma ao próprio tipo de produção, pois a definição mais conhecida do jornalismo imersivo refere-se "à produção de notícias na forma em que as pessoas possam ter experiências em primeira pessoa de eventos ou situações descritas nas reportagens"1 (DE LA PEÑA et al., 2010, p. 291, tradução nossa). Outros autores também fazem referência à experiência possibilitada através da interação de usuários com produtos jornalísticos imersivos (ARCHER; FINGER, 2018; BRAUTOVIĆ; JOHN; POTREBICA, 2017; DOMÍNGUEZ, 2017; OWEN et al., 2015; SÁNCHEZ LAWS, 2017; SHIN; BIOCCA, 2017; SUNDAR; KANG; OPREAN, 2017).

Contudo, identificamos que a maior parte dos trabalhos não explora o conceito de experiência na relação do jornalismo com a imersão. Apenas citam-no. O objetivo deste artigo é propor um quadro teórico para a análise da experiência no jornalismo imersivo. De abordagem qualitativa, a investigação que dá base para este trabalho foi realizada a partir da combinação entre a pesquisa bibliográfica e a análise de produtos por meio do estudo de casos compostos por reportagens imersivas publicadas pelo The Guardian e The New 
York Times. As principais variáveis necessárias para a investigação da experiência em produtos jornalísticos imersivos contemplam quatro níveis de análise: epistêmico, estratégico, estilístico e estético. Além de dialogar com as reflexões sobre a experiência que trazemos a seguir, o framework foi elaborado tendo como inspirações as propostas de Hermann (2016) para a análise do jornalismo etnográfico e de Ellis et al. (2017) para a Teoria Estruturada da Experiência.

\section{Conceito de experiência \\ e 0 jornalismo imersivo}

Para entender o sentido da palavra experiência aplicada ao jornalismo imersivo fizemos um percurso bibliográfico e reflexivo, sem aspirar, contudo, apresentar respostas definitivas. Diante da vasta literatura disponível, apontamos linhas de raciocínio que se mostram como caminhos para o que tratamos aqui. Optamos por abordar preferencialmente, mas não apenas, autores que relacionam de algum modo experiência, comunicação e mídia, atendendo de forma mais pontual os interesses deste trabalho.

Erfahrung e Erlebnis são duas palavras alemãs que estão fortemente presentes na bibliografia sobre experiência. Ambas, se traduzidas para o português, significam experiência. Contudo, alguns pesquisadores perceberam que elas não têm o mesmo significado. De acordo com Castro (2015), a primeira delas Erfahrung-significa descobrir um conhecimento, algo que demanda esforço intelectual, uma travessia. "A experiência do Erfahrungé, em síntese, da ordem daquilo que, em português, dizemos por 'ter experiência”' (p. 61). A segunda - Erlebnis - ao contrário da primeira, não evoca grandes esforços intelectuais, nem definições prévias. Refere-se a algo fragmentado, não cumulativo e momentâneo. “[..] a experiência do tipo Erlebnis, seria da ordem de um estar-aí, de algo próprio à vida quotidiana" (p. 61).

A partir dessas duas palavras, o pensador Walter Benjamin, um dos mais citados pelos autores da Comunicação, foi além da etimologia. De acordo com Mateus (2014a), no pensamento benjaminiano, Erfahrung é uma experiência autêntica baseada nas ideias de tradição e comunidade. A temporalidade é lenta e cumulativa. Já Erlebnis está centrada no indivíduo, na consciência e na percepção isolada. A temporalidade é fragmentada, não cumulativa e baseada no imediato. Segundo Mateus (2014b), Benjamin afirma ser Erlebnis o enfraquecimento da experiência autêntica causada, sobretudo, pelo modo de vida da modernidade devido aos sucessivos choques (estéticos, políticos, culturais). Dessa forma, Erlebnis não é entendida como uma experiência autêntica, mas como uma vivência. 
Ao falar sobre a obra de arte, Benjamin (1994a) destaca a importância da autenticidade como sendo o instante exato da existência da obra para o indivíduo, no lugar pontual onde ela se encontra. Assim, a reprodutibilidade técnica, por mais perfeita que seja, carece de autenticidade, sendo, portanto, uma experiência empobrecida, uma vivência. Seguindo este raciocínio, podemos supor metaforicamente que o jornalismo é um tipo de reprodução técnica do fato, que utiliza as ferramentas de cada mídia para fazer a reprodução e apresentar ao público. As pessoas presentes fisicamente "aqui e agora" no lugar onde o fato originalmente aconteceu tiveram a experiência ligada à autenticidade. A reprodução dessa experiência faz com que, por meio de uma vivência, outras pessoas tenham contato com esse acontecimento. $\mathrm{O}$ jornalismo, portanto, aproxima do público a experiência de quem estava lá. Assim, apesar de não experienciar o fato autêntico em si, a vivência de entrar em contato com a reprodutibilidade técnica dele feita pelo jornalismo é uma importante ferramenta para a compreensão do mundo, a interpretação da vida e a formação de opinião das pessoas.

Porém, é essencial destacar que no pensamento benjaminiano a falta de autenticidade de uma reprodução técnica também é causada pela manipulação de quem faz a reprodução. O autor explica que, ao ser reproduzida tecnicamente, uma obra de arte, uma paisagem ou qualquer outro objeto estão à mercê do ângulo de observação de quem reproduz. Ao falar sobre a reprodução técnica através da fotografia, por exemplo, Benjamin (1994a, p. 168) pontua que a câmera é “[...] ajustável e capaz de selecionar arbitrariamente o seu ângulo de observação [...]. Ela pode, também, graças a procedimentos como a ampliação ou a câmera lenta, fixar imagens que fogem inteiramente à ótica natural". A reprodução é também carente da aura que só a experiência autêntica possui. A aura está ligada a elementos únicos espaciais, temporais, contextuais e estéticos do "aqui e agora", que a reprodução técnica, por mais aproximada que seja, jamais alcançará (BENJAMIN, 1994a).

Continuando o paralelo do pensamento benjaminiano com o jornalismo, essa manipulação corresponderia ao enquadramento do fato e à tradução do real feitos pelo jornalista, cinegrafista e outros profissionais do jornalismo. Assim, a reprodução técnica de um acontecimento não corresponde à experiência autêntica, mas sim a uma versão mediada. Mesmo no jornalismo imersivo, que utiliza ferramentas como áudios gravados no momento do acontecimento, vídeos em $360^{\circ}$ e imagens geradas por computador (CGIS) para imergir o espectador em ambientes nos quais ele pode escolher o ângulo de observação e interagir, existem enquadramentos e diversas escolhas 
feitas na produção e na edição. Como resultado, é oferecida ao público uma reprodução técnica da experiência autêntica não como ela de fato é, mas com todos os aspectos ligados à falta de autenticidade e à manipulação características do discurso jornalístico que em nenhuma hipótese é uma versão direta e neutra da realidade.

A partir desse raciocínio, consideramos que o jornalismo imersivo é uma forma de aproximação da experiência autêntica dos fatos, do "aqui e agora". Ao estar imerso, o usuário tem experiências em primeira pessoa, desenvolvendo a sensação de presença e empatia (DE LA PEÑA et al., 2010). Seria, portanto, uma vivência criada com a intenção de fazer uma aproximação sensorial da experiência autêntica, através de equipamentos tecnológicos digitais. Assim, a diferença da ideia de experiência relacionada ao jornalismo imersivo e aquela ligada a outros tipos de jornalismo é que assistir televisão, ler um texto ou ouvir rádio são vivências relacionadas a estar diante de formas de apresentação dos fatos. Já a vivência, no caso do jornalismo imersivo, estaria relacionada a, de alguma forma, experienciar uma versão mediada dos fatos, embora haja uma percepção minimizada da mediação. Ou seja, o espectador não se sente diante da mídia, como nas outras formas de jornalismo, mas há uma emulação de que ele está diante dos fatos. Seria uma forma de fazer o espectador se sentir coabitando com os fatos (DE LA PEÑA et al., 2010), sem, porém, viver a experiência autêntica em si.

Em outro texto, Benjamin (1994b) destaca que a informação advinda da narrativa jornalística, sendo apenas uma forma de reportar e explicar fatos da realidade imediata usando os princípios da novidade, brevidade e clareza, empobrece a experiência. Contudo, no jornalismo imersivo em particular, a carência da dimensão experiencial ligada à narrativa jornalística, alegada por Benjamin, seria amenizada, porém não superada, visto que ele visa justamente intensificar o caráter experiencial por meio da imersão.Além de considerarmos as mídias em geral ao mesmo tempo como ferramentas para a comunicação de experiências (MATEUS, 2014b) e formas de apreensão do mundo (CARDOSO FILHO; MARTINS, 2010), compreendemos o jornalismo imersivo como um tipo de experiência mediada (GUIMARÃES; LEAL, 2008) que busca de forma mais enfática fazer as pessoas se sentirem no lugar do outro. Essa reflexão se encaixa tanto na experiência de imersão do usuário quanto na experiência de imersão do repórter. Com este último acontece através de uma apuração in loco, fora da lógica da cobertura instantânea do factual, quando o repórter experiencia os fatos para em seguida desenvolver a peça jornalística, em um movimento descrito em Cramer e McDevitt (2004) e Hermann (2016) 
como jornalismo etnográfico. Ou seja, um modelo que explora técnicas de coleta de dados das ciências sociais, como a observação participante, para criação de narrativas aprofundadas. A imersão do repórter, portanto, contribui para a imersão do usuário, pois quanto mais o primeiro se aproxima da experiência do fato autêntico, maior o potencial de aproximação do segundo. Essa aproximação prediz a principal característica do jornalismo imersivo, que é a intenção de promover uma experiência em primeira pessoa dos fatos (DE LA PEÑA et al., 2010).Essas reflexões nos apontam um dos caminhos possíveis para a compreensão do que seria experiência no jornalismo imersivo. Os elementos trazidos por Walter Benjamin tais como Erfahrung, Erlebnis e reprodução técnica não foram abordados aqui de forma literal, tal e qual foram desenvolvidos pelo autor. Foram usados como inspiração e metáfora, de forma a incitar a criação de linhas de raciocínio. Assim, mesmo estando no conceito de jornalismo imersivo a noção de "experiência em primeira pessoa" e sendo o objetivo principal fazer o público "experienciar o fato", isso não corresponde à promoção da experiência autêntica. É imprescindível trazer essa lucidez para as discussões para que a ideia de experiência nos formatos imersivos não passe a falsa conotação de autenticidade. Além disso, a impressão de não mediação, importante característica da realidade virtual responsável em parte por promover a imersão e potencializar o caráter experiencial tão ressaltado e pouco refletido, não deve ser utilizada como disfarce para passar um discurso de correspondência direta com a realidade. $O$ jornalismo não deve se colocar, nem ser colocado com esse papel.

\section{A experiência estética}

O filósofo John Dewey, contemporâneo de Walter Benjamin, também é bastante citado na bibliografia sobre experiência, mais precisamente sobre experiência estética e estética da comunicação. Para o autor, a experiência é resultado da interação entre o indivíduo e o ambiente, ou seja, entre a criatura e algum aspecto do mundo no qual se vive. Porém, ela acontece num fluxo incessante no qual as partes que a compõem mantêm uma identidade, como se fossem várias experiências que juntas formam a experiência inteira (DEWEY, 1980).

Sobre a experiência estética, Valverde (2010) afirma ser caracterizada pela imersão do indivíduo numa região do mundo sensível. Mesmo a internet, que transforma imagens em estruturas numéricas, não suspendeu a sensibilidade. Mas houve um deslocamento da estética, "passando a ser a teoria de uma experiência sem corpo" (p. 6). Para Valverde (2019), a estética da comunicação está relacionada a uma hermenêutica do sensível, a partir do entendimento de que a comunicabilidade estética está situada no âmbito da 
sensibilidade e o sentido é anterior aos significados codificados.

Sobre a experiência estética, Marques e Martino (2015) afirmam que não seria uma recepção, mas uma percepção compreendida quando é atribuído um sentido, que acontece no momento do compartilhamento do sensível. Essa ideia se aproxima da vivência relacionada à empatia e às sensações que seriam desenvolvidas durante o contato com reportagens jornalísticas imersivas em realidade virtual (DE LA PEÑA et al., 2010). Está ligada ao pensar e sentir o outro, demandando um envolvimento para além do cognitivo. "[...] uma dimensão estética da comunicação sublinha o aspecto de sentir o outro, não apenas entendê-lo na formação de um entendimento comum, mas também na partilha de uma sensibilidade comum" (MARQUES; MARTINO, 2015, p. 37).

O jornalismo imersivo seria, assim, uma forma de experiência, reconhecida como vivência, que busca uma aproximação da experiência autêntica por meio da imersão. É resultado da interação do indivíduo com o ambiente (DEWEY, 1980), do indivíduo com o mundo (MARQUES; MARTINO, 2015) e do contato entre indivíduos, um "ser-com-outros" (CASTRO, 2015). Contudo, esse ambiente, esse mundo e esse outro não fazem parte do mundo material, no momento da vivência, mas da imaterialidade do ciberespaço, que hoje não é considerado simploriamente um espaço de simulação da vida, mas uma forma desmaterializada de acontecer a própria vida (REZENDE; BEDRAN, 2015).

Valverde (2010) aponta ainda que a experiência estética é uma saída para o objetivismo científico. Segundo ele, pesquisadores do campo são demandados a configurar suas investigações de forma a cumprirem com requisitos rígidos da epistemologia científica, oriunda das tradições de pesquisa do campo das ciências naturais, para terem seus conhecimentos validados. A ocultação da experiência é um elemento implícito no projeto de ciência moderna e que pode ser superada pela estética.

Ao deslocarmos este raciocínio para o campo jornalístico é possível pontuar muitas similaridades. O projeto científico moderno foi inspirador para a formulação de uma epistemologia da objetividade jornalística, que agregasse credibilidade, autoridade e profissionalismo, junto à esfera pública (NEVEU, 2004; SCHUDSON, 2003). Foram desenvolvidas técnicas de apuração e escrita, bem como valores profissionais foram construídos, no sentido de garantir uma apresentação do mundo mais verossímil. (CARLSON, 2017; SEIDENGLANZ; SPONHOLZ, 2009). Por outro lado, o modelo elaborado não é capaz de explicar 
os complexos problemas do mundo contemporâneo porque elimina detalhes, fragmenta e deixa várias lacunas abertas. Uma das consequências é a emergência de atores independentes capazes de compreender os processos de circulação de discursos em plataformas digitais e de disputar sentidos com o jornalismo, que instauram cenários de caos com um fluxo de informações imprecisas e graves impactos na tomada de decisões políticas por parte dos cidadãos.

Oliveira, Osório e Henn (2019) defendem a necessidade de uma reação do jornalismo no investimento de uma mediação qualificada, ou seja, formas mais complexas de representação e interpretação do mundo, do que àquelas oferecidas pelos amadores. Neste sentido, os dados aparecem como importantes ferramentas de rastreio, apoio às análises profundas e às estratégias de circulação deste tipo de conteúdo.

Outra reação possível é o investimento em esforços que tentem se aproximar de uma experiência autêntica por meio do jornalismo imersivo. Ainda faz sentido a defesa de Thompson (1998) que argumenta que a experiência mediada continua sendo diferente porque é sequestrada do seu fluxo normal e reconfigurada pela linguagem da mídia. Entretanto, usar a comunicação para tratar de temáticas de modo profundo e acompanhar o curso de uma experiência de forma mais ampla, leva à criação de produtos com o potencial de provocar transformações internas nos sujeitos e gerar conhecimentos diferentes que as narrativas tradicionais não o fazem.

A partir dessas reflexões, vê-se a necessidade de um maior aprofundamento analítico. Portanto, além de entender a que nos referimos quando falamos em experiência no jornalismo imersivo, é necessário analisar como os produtos imersivos são configurados para potencializar essa experiência. Em vista disso, buscamos refletir sobre as múltiplas facetas da experiência dentro do jornalismo imersivo para desenvolver o framework.

\section{Quadro teórico para análise da experiência no jornalismo imersivo}

A análise da experiência no jornalismo imersivo oferece algumas vantagens para a compreensão dos recursos, possibilidades e apropriações da realidade realizadas pelos meios jornalísticos. A primeira é a compreensão de estratégias e decisões tomadas pelos agentes produtivos na criação de produtos. A outra vantagem é a percepção de como se dão processos de mudanças e transformações no campo jornalístico (BOURDIEU, 1997) que podem resultar em inovações, no sentido proposto por Echeverría (2017, p. 21, tradução nossa) como sendo "processos interativos que geram algo novo, transformador e valioso em 
sistemas e entornos determinados" ${ }^{2}$. Por fim, uma análise deste tipo também pode sugerir modos de potencializar as experiências permitidas a partir do encontro entre agentes produtivos e acontecimentos ${ }^{3}$ e produtos e usuários.

A complexidade do conceito de experiência e sua relação com o jornalismo, no entanto, tornam difícil a definição de parâmetros para a análise da experiência no jornalismo imersivo. Quais categorias, operadores e características podem ser observados (e em que lugar) para fornecer este tipo de diagnóstico? O esforço em empreender uma investigação das formas como produtos jornalísticos imersivos são configurados para potencializar experiências precisa ser amplo o suficiente para contemplar este conceito multifacetado, mas ao mesmo tempo restrito para ser operacional e abarcar as particularidades do campo jornalístico. Neste sentido, na formulação de uma proposta de quadro teórico para a análise da experiência no jornalismo imersivo, nos inspiramos no modelo proposto por Hermann (2016), que analisa de modo holístico o jornalismo etnográfico; e na Teoria da Experiência Estruturada apresentada por Ellis et al.
(2017), que se dedica a oferecer proposições sobre como a interação de sujeitos com serviços ligados ao lazer organizados de modo estratégico podem resultar em experiências subjetivas importantes para esta indústria.

O trabalho de Hermann (2016) oferece uma forma de observação do jornalismo etnográfico que consegue capturar mudanças, levando em consideração aspectos epistemológicos (ETTEMA; GLASSER, 1984; TAMBOSI, 2003), bem como técnicos, ligados às tomadas de decisões estratégicas do ponto de vista da produção da narrativa jornalística e do produto final. Este modelo estende as fronteiras do jornalismo, segundo a autora, porque rompe com estilos tradicionais de apuração e escrita. A proposta aponta três níveis: epistêmico, estratégico e estilístico.

Já a investigação de Ellis et al. (2017) está fundamentada em uma demanda essencial para a indústria e pesquisa no campo do turismo, estudos do lazer e marketing sobre as experiências de consumidores. Segundo os autores, a experiência estruturada é definida como: “[...] um conjunto estendido por um 
provedor de experiência (por exemplo, uma estrutura manipulada) para um estado subjetivo elevado de motivação, atenção e emoção para ocorrer" (ELLIS et al., 2017, p. 3-4). Entre os exemplos estão a participação em jogos e festivais. A contribuição desses autores está em apresentar categorias da experiência subjetiva. De acordo com eles, imersão, absorção e engajamento precisam ser analisados em circunstâncias específicas e objetivamente. Entre as circunstâncias estão a natureza da situação, a presença ou ausência de demandas de ação comportamental e a extensão da participação envolvida.

Inspirados nas duas propostas, que partem de formulações e desafios teórico-metodológicos que têm similaridades com o presente trabalho, elaboramos um caminho de investigação dividido em quatro níveis inter-relacionados: epistêmico, estratégico, estilístico e estético. Em cada nível, são analisados alguns aspectos teóricos-técnicos e procedimentos que potencialmente têm sido explorados pelos produtos jornalísticos imersivos, que fazem parte do nosso corpus e têm relação com o conceito de experiência. Foram desenvolvidas técnicas de apuração e escrita, bem como valores profissionais foram construídos para garantir uma apresentação do mundo mais verossímil. (CARLSON, 2017; SEIDENGLANZ; SPONHOLZ, 2009).

Trabalhamos com quatro peças jornalísticas em realidade virtual, duas produzidas pelo jornal britânico The Guardian e duas pelo estadunidense The New York Times. A escolha destes meios e dessas peças se deu pela continuidade da produção e pela qualidade das reportagens em realidade virtual atestada em premiações de entidades internacionais. Pelo meio britânico, a reportagem $6 \times 9(2015)^{4}$, feita a partir de CGIs, insere o usuário dentro de uma cela de confinamento e traz informações sobre dificuldades e dramas psicológicos vivenciados por um encarcerado. Já a reportagem em vídeo $360^{\circ}$ The Party $(2016)^{5}$, coloca o usuário no lugar da adolescente autista Layla durante a festa de aniversário da sua mãe e, através do fluxo de consciência, nos dá acesso aos seus pensamentos e angústias diante daquele evento. Pelo meio estadunidense, a reportagem The Displaced $(2015)^{6}$ relata a história de três crianças que saíram de suas casas em

4 Disponível em: <https://www.theguardian.com/world/ng-interactive/2016/apr/27/6x9-a-virtual-experience-of-solitaryconfinement>. Acesso em: 10 jan. 2019.

5 Disponível em: <https://www.theguardian.com/technology/2017/oct/07/the-party-a-virtual-experience-of-autism-360video>. Acesso em: 10 jan. 2019.

6 Disponível em: <https://www.nytimes.com/video/magazine/100000005005806/the-displaced.html>. Acesso em: 11 jan. 2019. 
decorrência de guerras em seus territórios por meio de uma imersão do usuário nos ambientes destruídos. Já a reportagem The Fight for Falluja (2016) ${ }^{7}$ coloca o usuário no meio do campo de batalha entre o Estado Islâmico e o exército iraquiano durante a recuperação da cidade de Falluja.

\section{Nível epistêmico}

Definido a partir da lógica interna e suposições em que se baseia a investigação jornalística de modo explícito ou implícito (HERMANN, 2016), o nível epistêmico aborda aspectos ligados à epistemologia jornalística. De acordo com Ekstrom (2002) e Matheson (2004), a epistemologia jornalística, do ponto de vista da sociologia do conhecimento, diz respeito às regras, rotinas e procedimentos institucionalizados que resultam em conhecimentos para o próprio campo. Questões epistemológicas levantam discussões sobre a objetividade e a verdade no debate sobre cultura jornalística em Hanitzch et al (2007) e em Tambosi (2003), sobre a precisão e veracidade no jornalismo investigativo (ETTEMA; GLASSER, 1984), além das rotinas e procedimentos dos weblogs e tendências do jornalismo on-line (MATHESON, 2004), do telejornalismo (EKSTRÖM, 2002) e do jornalismo de dados (LEWIS; WESTLUND, 2015).
A partir da observação do corpus, centraremos este nível na análise da experiência no jornalismo imersivo nos conceitos de objetividade e transparência. A objetividade jornalística, que vem do positivismo, tem abordagens: a) de ordem ontológica, sobretudo nos discursos que historicamente construíram a atividade, como mostram Chalaby (1998), Schudson (2003) e Tuchman (1972); b) de ordem procedimental, como o ouvir todos os lados de uma história e garantir a pluralidade de vozes (DEUZE, 2008; GUERRA, 1998; MARAS, 2013); e c) de ordem epistemológica, como mostram Seidenglanz e Sponholz (2009), ao discutirem sobre os padrões de verificação da realidade e o viés de orientação do profissional que garante qualidade jornalística. Para a presente análise, o foco está em seu viés procedimental.

Do ponto de vista do conceito de experiência, a objetividade jornalística é vista como um obstáculo. Benjamin (1994a), Bondía (2002) e Mateus (2014a) explicam que a atuação da imprensa fundamentada em seus princípios jornalísticos empobrece a experiência porque o foco está na novidade, na brevidade e no relato dos acontecimentos de modo distanciado e superficial. Porém, Domínguez (2013) analisa características que compõem uma 
retórica imersiva, colocando o usuário em uma posição em que ele tem a sensação de estar diante da realidade e pode atuar nela, nos casos de narrativas imersivas. Não se trata de uma ocultação da objetividade neste tipo de produto, mas de uma reconfiguração do conceito a partir das novas possibilidades narrativas em $360^{\circ}$.

Aitamurto (2018) levanta entre seus paradoxos normativos que a precisão ajuda a definir a objetividade e pode ser vista como uma característica afetada negativamente e positivamente com os vídeos $360^{\circ}$. O volume de informação sobre um ambiente inteiro, como nos casos das reportagens do The New York Times que envolvem cenários de guerra, e não mais a seleção daquilo que seria mais importante, vai de encontro às normas jornalísticas. Por outro lado, a possibilidade de um relato que ofereça mais detalhes sobre um cenário, personagens e ação, estaria totalmente de acordo com os princípios jornalísticos. Assim, uma visão da objetividade jornalística que a) se preocupa em correlacionar a realidade midiática à realidade social, b) que evita percepções falsas, como sugere Sponholz (2009), e c) que explora, por exemplo, métodos do jornalismo etnográfiCO (CRAMER; MCDEVITT, 2004; HERMANN, 2016) ou seja, sem implementar uma retórica do distanciamento, está potencialmente mais próxima de oferecer uma experiência mais complexa e menos sujeita às críticas recebidas pelo jornalismo tradicional - produzido cotidianamente por meios considerados como referência na esfera pública pelo alcance da marca e dos seus produtos, imagem e credibilidade construídas ao longo do tempo na sociedade.

Nas reportagens do The Guardian, os usuários são colocados nos lugares de personagens que compõem a narrativa relatada. Há, inclusive, fluxo de consciência, recurso incompatível com o ideal de objetividade. O impacto deste tipo de configuração de produto para a experiência é despertar emoções e permitir novas formas de interação entre sujeitos e aspectos do mundo, rompendo com um modelo de reportar fragmentado e que impacta negativamente na experiência autêntica defendida por Benjamin (1994a). Além disso, vai ao encontro da dimensão estética da experiência que traz a ideia de sentir o outro a partir da partilha de uma sensibilidade comum (MARQUES; MARTINO, 2015).

Ao mesmo tempo, estas estratégias também forjam uma sensação de que o conteúdo não está sendo mediado; mesmo tratando-se de uma peça em CGIs, em $6 \times 9$, e, no caso de The Party, um vídeo $360^{\circ}$ com atores encenando uma situação que foi apurada pela equipe jornalística. Essa sensação de não mediação ganha força quando o conteúdo 
é consumido com os óculos de realidade virtual, visto que as bordas da tela não são vistas pelo usuário. Este se vê no meio da cena com a possibilidade de olhar para os lados e escolher o ângulo de visão.

A transparência é outro conceito importante para o nível epistêmico. O conceito de objetividade tem como pano de fundo a simulação de uma não mediação do acontecimento pelo jornalista. Neste sentido, a escrita em terceira pessoa e a omissão de opiniões e interpretações no texto jornalístico tradicional, por exemplo, são estratégias que conferem credibilidade e veracidade à narrativa jornalística porque dão a sensação de não mediação. Com a tecnologia de realidade virtual, a transparência ganha novas características e o encontro entre sujeitos e a realidade social por meio de um aparato midiático também. Bolter e Grusin (2000) chegam até a criticar a ideia da "mediação perfeita" possibilitada pela realidade virtual.

O filósofo francês Trentini (2014) vai além e defende que a imersão não transparente é importante para este tipo de experiência estética. Segundo ele, sempre estaremos diante de códigos, mais fáceis ou não, durante uma experiência de imersão. Contudo, o que garante uma boa imersão está mais ligado à naturalização do código pelo usuário do que uma tentativa de não transparência. A análise da experiência no jornalismo imersivo no que diz respeito à transparência, portanto, precisa observar quais características presentes nos discursos e estratégias de agentes produtivos estão compatíveis com este conceito.

Na descrição da reportagem The Fight for Falluja, por exemplo, há o convite para que o usuário tenha uma "experiência em primeira mão" das batalhas do exército iraquiano para recuperação da cidade de Falluja. "Experiência em primeira mão" é uma expressão que denota uma ausência de intermediários; assim como "experiência em primeira pessoa", que está na definição de De La Peña et al. (2010) e a expressão "in the shoes of", que aparece na descrição de The Party, do The Guardian, e significa "na pele de" ou "no lugar de".

O nível epistêmico se configura, desta forma, a partir da existência de elementos que ajudam a legitimar o jornalismo ligando-o ao conhecimento ou à verdade. Há a inserção de elementos subjetivos, como pontos de vista e detalhes além do fato em si e até a percepção do agente produtivo pode ser incluída na peça que não limita ou simplifica a complexidade do mundo social em uma narrativa jornalística do cotidiano. Nos casos observados, objetividade e transparência aparecem como conceitos que rompem ou atualizam regimes epistêmicos do jornalismo com reverberações diretas ao conceito de experiência. 


\section{Nível estratégico}

O nível estratégico é caracterizado pelos métodos empregados na rotina jornalística. No jornalismo etnográfico, segundo Hermann (2016), é preciso romper convenções profissionais, como a imersão junto às fontes, o exercício da empatia e o tempo de produção. O impacto desse processo de imersão na vida e cotidiano de um determinado grupo social estudado levanta questões éticas para a profissão, como a objetividade e o equilíbrio, mas permite um retrato mais autêntico a partir de um melhor entendimento de sentimentos e valores daquilo que está sendo reportado (CRAMER; MCDEVITT, 2004).

As reportagens em realidade virtual demandam novas preocupações relacionadas às capturas ou geração de imagens e do áudio para forjar uma experiência que tenha "efeito de real". Em 6x9, o cenário de uma cela é construído com o auxílio de software para permitir que o usuário possa explorar aquele ambiente (Figura 1). A partir de 2015, com a maior disseminação das câmeras de captura em $360^{\circ}$ nas redações, de acordo com Hardee e McMachan (2017), houve uma possibilidade maior de desenvolvimento de produtos em narrativas imersivas. Segundo os autores, os vídeos $360^{\circ}$ têm a vantagem de demandar menos recursos técnicos quando comparadas aos CGI.
Assim, do ponto de vista do nível estratégico, os agentes produtivos dos vídeos $360^{\circ}$ precisam tomar decisões relacionadas à forma de captura das imagens para criar uma experiência jornalística de realidade virtual. Em The Party, a solução foi a de encenar a presença de uma garota de 14 anos com espectro autista em uma festa de aniversário (Figura 1). Roteiro, atores e diretores são alguns elementos que fizeram parte desta produção que coloca o usuário no lugar da adolescente. São exploradas, portanto, características de produtos ficcionais para lidar com a informação jornalística de modo a tentar oferecer uma experiência estética que se afasta da avaliação apresentada em Benjamin (1994a), Bondía (2002) e Mateus (2014a) sobre o empobrecimento da experiência. A ideia foi usar a encenação para oferecer ao público uma aproximação da experiência autêntica de ser uma garota com espectro autista. O recurso não é novidade no jornalismo, uma vez que o uso da simulação é um artifício explorado pela prática jornalística com a finalidade de incrementar um relato jornalístico e permitir que sujeitos criem vínculos com a história. O telejornalismo e peças jornalísticas em redes digitais frequentemente exploram este recurso como elemento de ilustração. Nos vídeos $360^{\circ}$ do The New York Times, a solução foi capturar a ação enquanto ela transcorre para transmitir um senso de realidade. Em The Fight For Falluja, por exemplo, o repórter documenta sua experiência em 
meio a batalha junto com militares do exército iraquiano para a recuperação da cidade de Falluja do Estado Islâmico e a câmera $360^{\circ}$ simula o olhar do usuário diante daquela ação. Inserir o usuário no lugar do acontecimento como um observador é uma das principais preocupações deste tipo de produção, como afirmam Longhi (2018) e Longhi e Lenzi (2017).

Figura 1: Reportagens $6 \times 9$ (linha 1) e The Party (linha 2) do The Guardian

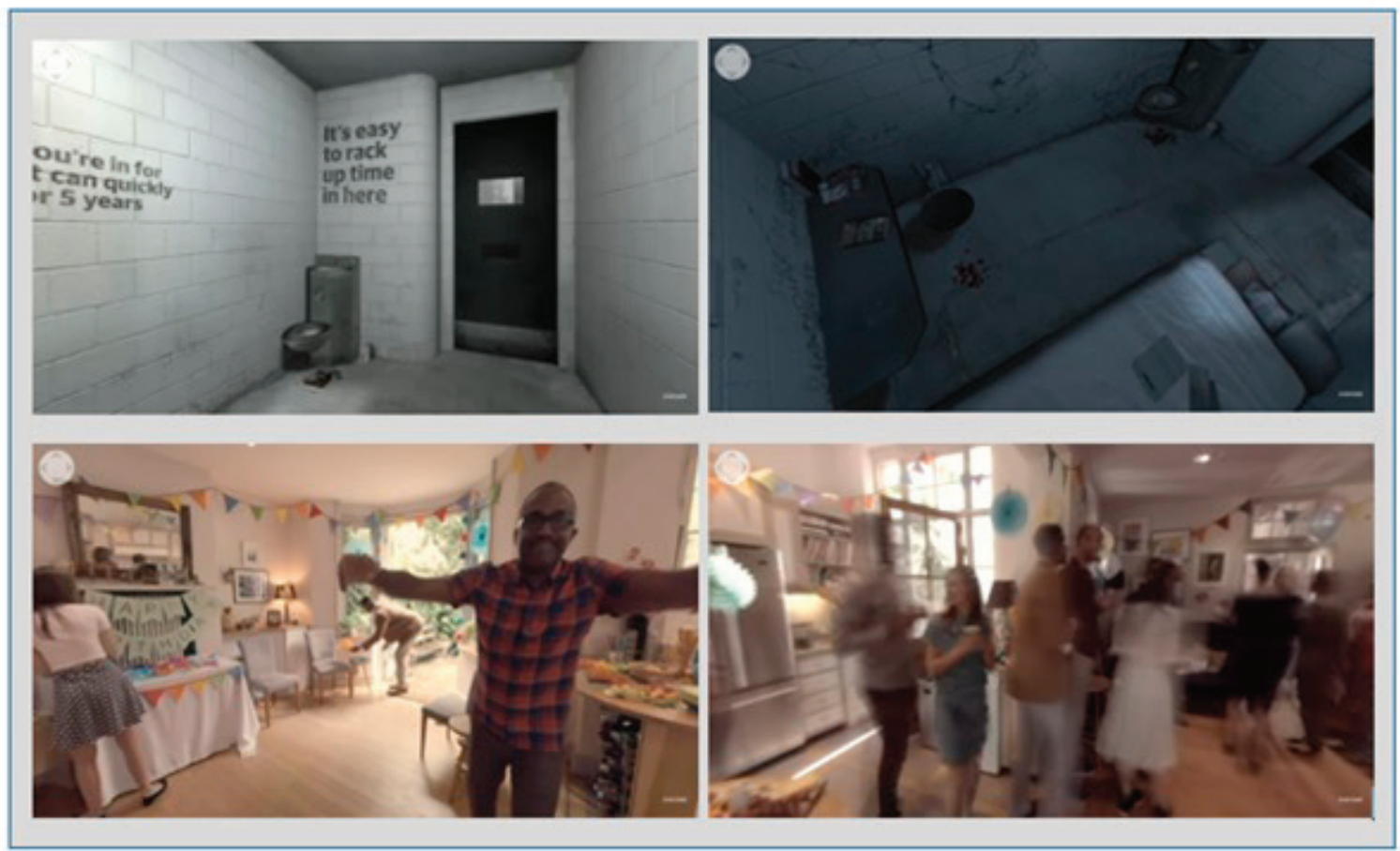

Fonte: Reprodução de reportagens.

Apesar de as reportagens imersivas se aproximarem mais da experiência autêntica e mesmo o usuário tendo uma maior autonomia ao poder escolher o ângulo de visão, ainda há, como preconizou Benjamin (1994a), a presença do enquadramento do acontecimento feito pelo repórter e pela equipe produtora. Esse enquadramento existe, porém, é menos evidente nesse tipo de produto. O nível estratégico de análise procura observar as decisões tomadas e as diversas ações que influenciam no ângulo de visão incluído inevitavelmente no produto jornalístico. Em se tratando de jornalismo imersivo, esse enquadramento do fato busca valorizar o caráter experiencial da reportagem. Em The Party, por exemplo, a equipe de reportagem decidiu que o ângulo de visão sobre o espectro autista a ser 
mostrado na reportagem propositalmente seria baseado em quem vive o próprio espectro autista e não na opinião de terceiros ou de especialistas.

Outro fator a ser observado é a dimensão do tempo, que no jornalismo imersivo também é readequada, nestes casos analisados, e assume uma dinâmica compatível com a experiência. Tanto na produção quanto na interação deste tipo de produto, geralmente, é preciso mais tempo do que no jornalismo tradicional. Em The Fight For Falluja, foram dois meses entre o evento (junho de 2016) e o lançamento (agosto de 2016), além de serem necessários mais de 11 minutos e 08 segundos para a fruição do vídeo. No telejornalismo, a média de uma reportagem é de pouco mais de um minuto, segundo Maciel (1995). Por sua vez, Jones (2017) afirma que há estudos que apontam que o tempo ideal para a imersão em uma narrativa é de dez minutos.

Neste sentido, o jornalismo que explora a realidade virtual vai na direção oposta aos apontamentos de Bondía (2002) sobre o fato de estarmos tendo experiências empobrecidas pelo excesso de informação, de opinião, de trabalho e escassez de tempo. Todos estes pontos listados pela autora passam pelo encurtamento do tempo que está no cerne da atividade jornalística mais corriqueira, que lida com o atual e a narração do tempo presente (FRANCISCATO, 2003; MOTTA, 2005; GROTH, 2011) e encontra nas tecnologias digitais possibilidades de potencializar ainda mais esta vocação com a atualização em tempo real e com a instantaneidade, por exemplo (BRADSHAW, 2014; CANAVILHAS, 2007; MIELNICZUK, 2003).

Com tempo mais longo no processo de produção e a necessidade de estar presente no lugar do acontecimento ou junto às fontes, o repórter que explora recursos imersivos tem o potencial de penetrar em mais camadas da dimensão do mundo social e pode configurar um tipo de experiência mais enriquecida. O nível estratégico ainda pode levantar novos aspectos teórico-técnicos e procedimentos ligados ao processo de produção, que agregam outras características do ponto vista da experiência, como o uso de trilhas sonoras para despertar emoções nos usuários ou a fixação da câmera $360^{\circ}$ em um veículo para permitir mais um tipo de movimentação no ambiente.

\section{Nível estilístico}

Uma prosa acessível, com uma composição que entretenha e mantenha um fluxo entre a coleta e a escrita são as características que fazem parte do nível estilístico no jornalismo etnográfico de Hermann (2016). Para a análise da experiência do jornalismo imersivo, a narrativa é o principal elemento que fornecerá aspectos importantes para observação. Além 
disso, recursos realizados na edição das peças também indicam técnicas e procedimentos que podem ser relacionados ao conceito de experiência.

Segundo Jones (2017), a disrupção do jornalismo que explora a realidade virtual está na capacidade de configuração de uma narrativa que alia conteúdo e aspectos tecnológicos de forma a não apenas apresentar o acontecimento, mas oferecer uma experiência. A autora caracteriza três tipos de narrativas nos vídeos $360^{\circ}$ produzidos pelo jornalismo: a) o social $360^{\circ}$ é aquele em que o usuário vê uma história em ação, como no caso de The Party; b) o conduzido pelo repórter reproduz muitas características do telejornalismo, como no caso de The Fight For Falluja (FIG.2); c) o conduzido pelo personagem direciona a força para a fonte direta da história e, segundo a autora, melhora a atenção e a compressão, como em The Displaced (Figura 2).

A tipologia de narrativas imersivas de Jones (2017) se preocupa ainda em classificar a forma como os personagens são apresentados nas peças. Este é apenas um aspecto possível de ser observado na análise narrativa, que Genette (1995) denomina de vozes das narrativas. Em $6 x 9$, realizado em CGIs, temos uma narrativa híbrida, conduzida pelo usuário que está no lugar de uma pessoa presa em uma cela de confinamento, que pode olhar para todos os lados, direcionada por vozes que relatam os problemas de passar 23 horas por dia em um ambiente como aquele, com apenas uma hora para o banho de sol. Há também o auxílio de texto escrito que aparece durante a exibição. O intuito é fortalecer a sensação de estar só, em um ambiente fechado e pequeno, sem interação com o exterior ou outras pessoas e remeter ao surgimento de conflitos psicológicos.

A narrativa de The Party também traz alguns aspectos importantes para o conceito de experiência. A apuração jornalística foi feita junto às fontes especializadas - pessoas portadoras de espectro autista e representantes de associações, e a redação foi feita por uma escritora autista, Sumita Majumdar, que refletiu sobre suas próprias experiências em situações similares. A voz da personagem também é representada por uma garota autista, Honey Jones. Assim, a encenação da situação e o fluxo de consciência foram as formas pelas quais os agentes produtivos encontraram para fazer espectadores imergirem no mundo sensível de uma pessoa portadora de autismo - uma tarefa que nem a medicina ainda consegue descrever com precisão.

A edição é mais um aspecto que influencia na configuração de experiências imersivas. Cortes, montagens e efeitos são exemplos de recursos explorados. Em Fight for Falluja, o repórter aparece em diferentes ambientes 
e leva o usuário junto com ele para dentro de um tanque de guerra, para trincheiras em um campo de batalhas - inclusive durante o conflito - e para o acampamento onde estão os refugiados. Em The Displaced, o usuário também é levado para diferentes ambientes, em cada um dos países das crianças refugiadas.

Figura 2: Reportagens The Fight For Fallija (linha 1) e The Diplaced (linha 2), do The New York Times

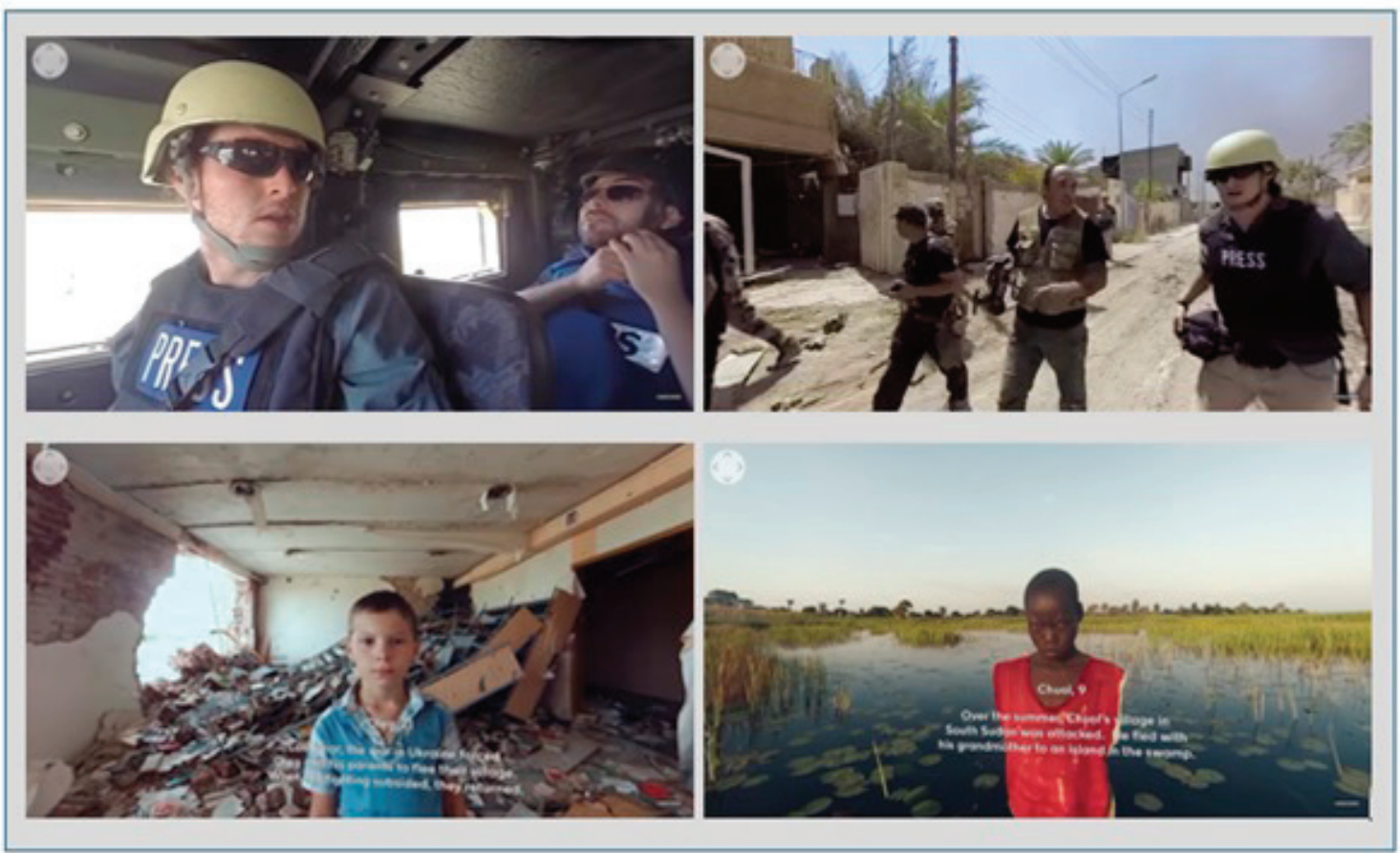

Fonte: Reprodução das reportagens.

Em The Party, efeitos na imagem dão a sensação do que a garota autista está sentindo durante a festa. Em determinado momento, a imagem fica nebulosa, os ruídos e pensamentos ficam confusos até que Layla perde os sentidos (fica tudo escuro) e reaparece no seu quarto, tentando identificar onde está e o que aconteceu. Assim, há a emulação de uma experiência de crise para uma pessoa portadora de autismo, sem usar o texto tradicional ou recursos imagéticos, que talvez não fossem capazes de dar uma dimensão mais precisa de um acontecimento do tipo.

Portanto, não há um formato específico de produtos em realidade virtual, com características estabilizadas. Dessa forma, no nível estilístico, o analista precisa perceber 
o conteúdo associado aos recursos narrativos explorados pelos agentes produtivos.

\section{Nível estético}

A experiência estética é definida pelo contato, encontro ou interação entre sujeitos e objetos (DEWEY, 1980; VALVERDE, 2010), a partir do entendimento de que o sentido flui espontaneamente, sendo anterior aos significados codificados (VALVERDE, 2019). Desta forma, a análise neste nível demanda a observação de aspectos teórico-técnicos e a exploração de procedimentos na investigação que envolvam sujeitos, bem como os seus relatos e reações. Aqui, indicamos algumas possibilidades de abordagem que compõem o nível estético, tendo como base a Teoria da Experiência Estruturada de Ellis et al. (2017), o conceito de imersão (MURRAY, 1997; RYAN, 2015) e atenção (BOULLIER, 2012; CITTON, 2017; DAVENPORT; BECK, 2001), bem como o de qualidade jornalística (GUERRA, 2011).

Qualidade, imersão, atenção e engajamento exercem influências mútuas e podem impactar negativamente experiências imersivas. A qualidade é definida operacionalmente por Guerra (2011, p. 5) como sendo a comparação entre características de produtos e requisitos “[...] a) necessários para o seu funcionamento; e b) esperados pelos usuários. Quanto mais próximas as características estiverem dos requisitos, maior a qualidade". No caso do jornalismo, os requisitos girariam em torno da relevância e da verdade, segundo o autor. Já os requisitos do jornalismo imersivo agregariam agenciamentos dos usuários, sensação de presença e conexão emocional, ou seja, elementos que estruturam a experiência.

A imersão é um dos conceitos-chave da Teoria da Experiência Estruturada e, segundo Ellis et al. (2017), ocorre quando um indivíduo começa a fazer parte da experiência, tamanha é sua motivação intrínseca, atenção focada e estímulo. Em Ryan (2015) e Murray (1997), as narrativas criadas no contexto de tecnologias digitais, com atributos como a interatividade, são o foco da análise sobre a imersão. Para elas, este processo psicológico está associado a deslocamentos mentais no espaço-tempo por meio de uma narrativa, que explora modelos cognitivos e repertórios de sujeitos e faz com que eles voltem transformados de suas jornadas.

A atenção é o processo que estrutura toda a experiência no nível estético porque se refere a uma atividade mental seletiva, de conexão durável, difícil de ser medida e fidelizada (BOULLIER, 2012; CITTON, 2017; DAVENPORT; BECK, 2001). Trata-se do instante inicial de uma interação que pode se expandir em uma experiência ou se tornar uma barreira. O grande problema da atenção na contemporaneidade, e que se reflete diretamente na 
Quadro 1: Resumo do quadro teórico

experiência, é a abundância de informação e a exposição a vários estímulos conjuntamente, que dificultam a concentração profunda e prolongada (CITTON, 2017). Medir atenção e conexão é uma tarefa difícil, segundo Boullier (2012), pela sua imaterialidade e falta de garantias. De acordo com o autor, adotam-se indicadores quantitativos de conexão com objetos, como a duração e intensidade do uso; utilizam-se grupos sociais para mensurar a duração e intensidade do fluxo; tecnologias de rastreamento ocular (eyetracking) que detectam traços de atenção pela fixação e movimento ocular; assim como as medidas psicológicas e de biomensuração e a opinião, além de canais de interação dialógica com usuários, como fóruns, comentários, blogs e microblogs.

O engajamento em Ellis et al. (2017) é definido como uma condição transitória de destaque da atenção, emoção e motivação no processo de fruição de uma narrativa. Em uma análise sobre a imersão, engajamento e presença em jogos digitais, McMahan (2003) sintetiza este conceito em três aspectos: uma entrada irracional no mundo do jogo, um investimento emocional e um estágio profundo de interação entre jogador e jogo. Em Shin e Biocca (2017), a experiência imersiva do jornalismo é descrita como dependente de uma posição de vontade ou de disposição em imergir. Já Sánchez Laws 
(2017) destaca a importância de despertar emoções para melhorar as respostas dos usuários e criar laços com estes tipos de conteúdo.

O nível estético de análise, portanto, fecha o framework proposto por este trabalho resumido no Quadro 1 -, incluindo múltiplas facetas da experiência do jornalismo imersivo que perpassam tanto pelos agentes produtores quanto pelos usuários.

Em consonância com a pluralidade de produtos jornalísticos imersivos, o quadro teórico elaborado neste artigo para a análise da experiência propõe um caminho de observação com múltiplas possibilidades. Além disso, a partir do corpus empírico escolhido, indicou que os produtos criados pelo The New York Times e The Guardian, por suas características e estratégias, tentam subverter o problema do empobrecimento da experiência na contemporaneidade, sobretudo na narrativa jornalística, listada pelos autores. Portanto, o quadro teórico deve ser usado para analisar tendências e, assim como indica Valverde (2010) no estudo da experiência estética, precisa ser aplicado na observação de um conjunto de produtos e contextos históricos. Novos produtos jornalísticos poderão indicar outras características dentro de cada nível.

\section{Considerações finais}

No jornalismo imersivo, os agentes produtivos exploram recursos técnicos e tecnológicos como auxiliares na configuração de uma narrativa sobre um acontecimento de forma que os usuários, ao se encontrarem com aquele mundo mediado, possam ter experiências mais complexas, que façam uma aproximação com às autênticas e sejam compatíveis com suas expectativas ao buscarem este tipo de produto.

Nesse contexto, o conceito de experiência é mais do que um atributo da relação entre usuários e os produtos jornalísticos em realidade virtual. Ao ser relacionado com a comunicação, a experiência é um complexo contributo de ordem metodológica que pode ampliar as compreensões de análise de produtos noticiosos imersivos e fornecer pistas sobre possibilidades de inovações no campo jornalístico (FONSECA, 2015; FRANCISCATO, 2010; MACHADO, 2010; PALACIOS et al., 2015).

Entretanto, uma análise do tipo de produto demanda uma visão holística da relação entre experiência e a atividade jornalística. Neste artigo, buscamos sintetizar a multidimensionalidade da experiência. A diretriz norteadora era entender o que significa afirmar que uma reportagem imersiva proporciona experiência e quais os aspectos teóricos que podem conformar um caminho de análise desta 
experiência. Percebeu-se que a noção de experiência acionada pelos agentes produtivos em seus discursos está na tentativa de promover uma aproximação da experiência autêntica, a Erfahrung, reduzindo, mas não superando, o caráter de empobrecimento e superficialidade daquilo que Walter Benjamin chama de vivência individual, a Erlebnis. Pelas características descritas, a Erlebnis estaria mais alinhada com o modo de existência da atividade jornalística, baseada em características como a atualidade, objetividade e neutralidade; e ligada às dinâmicas da sociedade contemporânea, com atenção fragmentada, excesso de informação e opinião e falta de tempo.

Os quatro níveis para a análise da experiência no jornalismo imersivo - epistêmico, estratégico, estilístico e estético - mostram uma inter-relação de experiências de agentes produtores, usuários e de expectativas de ambos os lados. Isto significa dizer que, no contexto apresentado, não há experiências puramente individuais e elas fazem parte de uma rede de agentes que compartilham emoções, ações, repertórios, visões de mundo e vivências. O framework construído com base em produtos jornalísticos valorados em premiações internacionais, ou seja, reconhecidos pelos pares como exemplo de inovação, é flexível o suficiente para a aplicação em diferentes peças.
A aplicação dele impõe alguns desafios ao pesquisador. O primeiro deles é a necessidade de múltiplas abordagens na investigação para a coleta de informação junto aos agentes produtivos, aos produtos e na interação com os usuários. O segundo deles é a natureza fluida dos níveis que encaminham a análise por diferentes caminhos a depender de quais produtos foram escolhidos. O terceiro desafio é a necessidade de análise de mais de um produto. Novos trabalhos voltados exclusivamente para a aplicação do framework devem ser empreendidos.

É importante ressaltar que este artigo visou apontar diversas questões envolvidas no desenvolvimento do conceito de experiência e na análise da experiência imersiva, trazendo ao debate elementos pouco abordados em trabalhos sobre jornalismo imersivo até então - conforme o levantamento bibliográfico realizado -, tais como o próprio conceito de experiência, as implicações e problematizações para o conceito de jornalismo, seus pilares e valores. Porém, é operacionalmente inviável aprofundar todas as questões levantadas em um único trabalho. A ideia é que pesquisas futuras possam aplicar oframework e fazer aprofundamentos a partir do que foi apontado aqui e de novos elementos que surgirem. 


\section{Referências}

AITAMURTO, Tanja. Normative paradoxes in $360^{\circ}$ journalism: Contested accuracy and

objectivity. New Media \& Society, p. 1-17, 2018.ALSINA, Miguel Rodrigo. La construcción de la notícia. Barcelona: Paidós Comunicación, 1993.

ALZAMORA, Geane; TÁRCIA, Lorena. Convergência e transmídia: galáxias semânticas e narrativas emergentes em jornalismo. Brazilian Journalism Research, v. 8, n. 1, p. 22-34, 2012.ARCHER, Dan.; FINGER, Katharina. Walking in Another's Virtual Shoes: Do 360-Degree Video News Stories Generate Empathy in Viewers? Columbia Journalism Review, 2018. Disponível em <https://www.cjr. org/tow_center_reports/virtual-reality-newsempathy.php> Acesso em: 20 maio 2019.

BARBOSA, Suzana. Jornalismo convergente e continuum multimídia na quinta geração do jornalismo nas redes digitais. In: CANAVILHAS, João (Org.). Notícias e mobilidade: 0 jornalismo na era dos dispositivos digitais. Covilhã, Portugal: UBI/ Labcom, 2013. p. 33-54.

BENETTI, Márcia. O jornalismo como acontecimento. In: BENETTI, Marcia; FONSECA, Virginia Pradelina da Silveira (Org.). Jornalismo e acontecimento: mapeamentos críticos. Florianópolis: Insular, 2010. p. 143-164. (v. 1).

BENJAMIN, Walter. A obra de arte na era de sua reprodutibilidade técnica. In: BENJAMIN, Walter. Magia e técnica, arte e política: obras escolhidas. 7. ed. São Paulo: Brasiliense, 1994a. p. 165-196.
BENJAMIN, Walter. O narrador: considerações sobre a obra de Nikolai Leskov. In: BENJAMIN, Walter. Magia e técnica, arte e política: obras escolhidas. 7. ed. São Paulo: Brasiliense, 1994b. p. 197-221.

BOLTER, Jay David; GRUSIN, Richard. Remediation: Understanding New Media. Cambridge: MIT Press, 2000.

BONDÍA, Jorge Larrosa. Notas sobre a experiência e o saber de experiência. Revista Brasileira de Educação, n. 19, p. 20-28, 2002. BOULLIER, Dominique. Lattention: un bien rare en quête de mesures. Sciences de la société, n. 87, p. 128-145, 2012.

BOURDIEU, Pierre. Sobre a televisão: seguido de a influência do jornalismo e os jogos olímpicos. Rio de Janeiro: Zahar, 1997.

BRADSHAW, Paul. Instantaneidade: Efeito da rede, jornalistas mobile, consumidores ligados e o impacto no consumo, produção e distribuição. In: CANAVILHAS, João. (Ed.). Webjornalismo: 7 caraterísticas que marcam a diferença. Covilhã, Portugal: LivrosLabCom, 2014. p. 111-136.

BRAUTOVIĆ, Mato; JOHN, Romana; POTREBICA, Marko. Immersiveness of News: How Croatian Students Experienced 360-Video News. In: DE PAOLIS, Lucio Tommaso; BOURDOT, Patrick; MONGELLI, Antonio (Ed.). Augmented Reality, Virtual Reality, and Computer Graphics. Cham, Suiça: Springer, 2017. p. 263-269.

CANAVILHAS, João. Webjornalismo. Da pirâmide invertida à pirâmide deitada. BOOC, p. 1-17, 2007.

CARDOSO FILHO, Jorge; MARTINS, Bruno. Presença e materialidade na experiência 
contemporânea. Alceu, v. 11, n. 21, p. 145-161, jul./dez. 2010.

CARLSON, Matt. Journalistic Authority: Legitimating News in the Digital Era. New York: Columbia University Press, 2017. CASTRO, Fábio Fonseca de. Intencionalidade, experiência banal e comunicação: esboço de prospecção fenomenológica do cotidiano. LOGOS 43, v. 22, n. 2, p. 58-70, 2015.

CHALABY, Jean. The Invention of Journalism. New York: St. Martin's Press, 1998.

CITTON, Yves. The Ecology of Attention. Ontario, Canadá: John Wiley \& Sons, 2017.

CRAMER, Janet; MCDEVITT, Michael. Ethnographic Journalism. In: IORIO, Sharon (Ed.). Qualitative Research in Journalism: Taking It to the Streets. Mahwah: Lawrence Erlbaum Associates Publishers, 2004. p. 127143.

DAVENPORT, Thomas; BECK, John. The Attention Economy: Understanding the New Currency of Business. Massachusetts: Harvard Business Press, 2001.

DE LA PEÑA, Nonny et al. Immersive Journalism: Immersive Virtual Reality for the First-person Experience of News. Presence: Teleoperators and Virtual Environments, v. 19, n. 4, p. 291-301, 2010.

DEUZE, Mark. Understanding Journalism as Newswork: How It Changes, and How It Remains the Same. Westminster Papers in Communication and Culture, v. 5, n. 2, p. 4-24, 2008.

DEWEY, John. Art as Experience. New York: Penguin, 1980.
DOMÍNGUEZ, Eva. Periodismo inmersivo: fundamentos para una forma periodística basada en la interfaz y en la acción. 2013. $304 \mathrm{f}$. Tese (Doutorado)-Universitat Ramon Llull, Barcelona, 2013.

DOMÍNGUEZ, Eva. Going Beyond the Classic News Narrative Convention: The Background to and Challenges of Immersion in Journalism. Frontiers in Digital Humanities, v. 4,p. 1-11, maio 2017.

ECHEVERRÍA, Javier. El arte de innovar: naturalezas, lenguajes, sociedades. Madrid: Plaza y Valdés, 2017.

EKSTRÖM, Mats. Epistemologies of TV Journalism: A Theoretical Framework. Journalism, v. 3, n. 3, p. 259-282, 2002.

ELLIS, Gary; FREEMAN, Patti; JAMAL, Tazim; JIANG, Jingxian. A theory of structured experience. Annals of Leisure Research, v. 22, n. 1, p. 97-118, 2017.

ETTEMA, James; GLASSER, Theodore. On the epistemology of investigative journalism.

Annual Meeting of the Association for Education in Journalism and Mass Communication, 1984.

FONSECA, Adalton dos Anjos. A inovação no jornalismo em revistas para tablets: uma análise a partir das affordances e da convergência de conteúdos jornalísticos. 2015. 252 f. Dissertação (Mestrado)-Universidade Federal da Bahia, Salvador, 2015.

FONSECA, Virgínia. O acontecimento como notícia: do conceito à prática profissional. In: BENETTI, Márcia.; FONSECA, Virgínia. (Ed.). Jornalismo e acontecimento: mapeamentos críticos. Florianópolis: Insular, 2010. p. 167185. (V. 1). 
FRANCISCATO, Carlos. A atualidade no jornalismo: bases para sua delimitação teórica. 2003. 336 f. Tese (Doutorado)Universidade Federal da Bahia, Salvador, 2003.

FRANCISCATO, Carlos. Uma proposta de incorporação dos estudos sobre inovação nas pesquisas em jornalismo. Estudos em Jornalismo e Mídia, v. 7, n. 1, p. 8-18, jun. 2010.

GENETTE, Gerard. Discurso da narrativa. Sinop: Arcádia, 1995.

GROTH, Otto. O poder cultural desconhecido: fundamentos da ciência dos jornais. Petrópolis: Vozes, 2011.

GUERRA, Josenildo. A objetividade jornalística. 1998. 186 f. Dissertação (Mestrado)-Universidade Federal da Bahia, Salvador, 1998.

GUERRA, Josenildo. Sistema de Gestão de Qualidade aplicado ao jornalismo: possibilidades e diretrizes. E-Compós, v. 13, n. 3, p. 1-16, 2011.

GUIMARÃES, César; LEAL, Bruno Souza. Experiência estética e experiência mediada. Intexto, Porto Alegre, v. 2, n. 19, p. 1-14, jul./ dez. 2008.

HANITZSCH, Thomas. Deconstructing Journalism Culture: Toward a Universal Theory. Communication Theory, v. 17, n. 4, p. 367-385, 2007.

HARDEE, Gary; McMAHAN, Ryan. FIJI: A Framework for the Immersion-Journalism Intersection. Frontiers in ICT, v. 4, p. 1-18, 2017.

HERMANN, Anne Kirstine. Ethnographic Journalism. Journalism: Theory, Practice \& Criticism, v. 17, n. 2, p. 260-278, 2016.
HODGSON, Kris. Immersive Storytelling: How 360-degree video storytelling is helping to redefine journalism. 2017. $111 \mathrm{f}$. Dissertação (Mestrado)-University of Alberta, Estados Unidos, 2017JENNETT, Charlene et al. Measuring and Defining the Experience of Immersion in Games. International Journal of Human Computer Studies, v. 66, n. 9, p. 641-661, 2008.

JONES, Sarah. Disrupting the Narrative: Immersive Journalism in Virtual Reality. Journal of Media Practice, v. 18, n. 2-3, p. 171185, 2017.

LEWIS, Seth; WESTLUND, Oscar. Big Data and Journalism. Digital Journalism, v. 3, n. 3, p. 447-466, 2015.

LIMA, Edvaldo Pereira. Jornalismo e literatura: aproximações, recuos e fusões. Anuário Unesco/Metodista de Comunicação Regional, v. 13, n. 13, p. 145-159, 31 dez. 2009

LONGHI, Raquel.; CAETANO, Kati. Valorexperiência no contexto do jornalismo experiencial. In: ENCONTRO NACIONAL DE PESQUISADORES EM JORNALISMO, 16., 2018, São Paulo. Anais...São Paulo: Associação Brasileira de Pesquisadores em Jornalismo, 2018.

LONGHI, Raquel; LENZI, Alexandre. Práticas ciberjornalísticas em Realidade

Virtual: inovação e impacto nos processos de produção. Revista FAMECOS, v. 24, n. 3, p. 268-280, 2017.

MACHADO, Elias. Creatividad e innovación en el periodismo digital. In: CONGRESO INTERNACIONAL DE CIBERPERIODISMO YWEB 2.0, 2., 2010, Bilbao. Anais... Bilbao: Universidaddel País Basco, 2010. 
MACIEL, Pedro. Jornalismo de televisão: normas práticas. Porto Alegre: Sagra; DC Luzzatto, 1995.

MARAS, Steven. Objectivity in Journalism. Cambridge: Polity Press, 2013.

MARQUES, Angela Cristina Salgueiro; MARTINO, Luis Mauro Sá. A comunicação, o comum e a alteridade: para uma epistemologia da experiência estética. LOGOS 43, v. 22, n. 2 , p. 31-44, 2015.

MATEUS, Sameul. A experiência e a vivência: proposta de uma teoria modular da comunicação. E-compós, Brasília, v.17, n.2, maio/ago. 2014a.

MATEUS, Samuel. Experiência e comunicação em Walter Benjamin. Interin, Curitiba, v. 17, n.1, p. 57-66, jan. /jun. 2014 b.

MATHESON, Donald. Weblogs and the Epistemology of the News: Some Trends in Online Journalism. New Media \& Society, v. 6 , n. 4, p. 443-468, 2004.

McMAHAN, Alison. Immersion, Engagement, and Presence. In: WOLF, Mark.; PERRON, Bernard (Ed.).The Video Game Theory Reader. New York, Routledge, 2003. p. 67-86.

MEDINA, Cremilda. A arte de tecer o presente: narrativa e cotidiano. São Paulo: Summus Editorial, 2003.

MIELNICZUK, Luciana. Jornalismo na web: uma contribuição para o estudo do formato da notícia na escrita hipertextual. 2003. $246 \mathrm{f}$. Tese (Doutorado)-Universidade Federal da Bahia, Salvador, 2003.

MOTTA, Luiz Gonzaga. A análise pragmática da narrativa jornalística. In: CONGRESSO BRASILEIRO DE CIÊNCIAS
DA COMUNICAÇÃO INTERCOM, 28., 2005, Rio de Janeiro. Anais... Rio de Janeiro: Intercom, 2005.

MURRAY, Janet. Hamlet on the Holodeck: The Future of Narrative in Cyberspace. New York: Free Press, 1997.

NEWMAN, Nick. Journalism, Media and Tecnology Predictions 2019. Oxford: Reuters Institute for the Study of Journalism; University of Oxford, 2019.

NEWMAN, Nick. Journalism, Media and Tecnology Predictions 2018. Oxford: Reuters Institute for the Study of Journalism; University of Oxford, 2018.

NOVAK, Thomas; HOFFMAN, Donna. Measuring the Flow Experience among Web Users. Interval Research Corporation, v. 31, n. 1, p. 1-35, 1997.

OLIVEIRA, Felipe Moura de; OSÓRIO, Moreno Cruz; HENN, Ronaldo Cesar. Agir Cartográfico: proposta teórico-metodológica para compreensão e exercício do jornalismo em rede. In: ENCONTRO ANUAL DA COMPÓS, 28, Porto Alegre. Anais... Porto Alegre: Pontifícia Universidade Católica do Rio Grande do Sul, 2019.

OWEN, Taylor; PITT, Fergus; ARONSONRATH, Raney; MILWARD, James. Virtual Reality Journalism: Tow Center for Digital Journalism. Columbia Journalism School, 2015.

PALACIOS, Marcos; BARBOSA, Suzana; FIRMINO, Fernando; CUNHA, Rodrigo. Jornalismo móvel e inovações induzidas por affordances em narrativas para aplicativos em tablets e smartphones. In: CANAVILHAS, João; SATUF, Ivan. (Ed.). Jornalismo para 
dispositivos móveis: produção, distribuição e consumo. Covilhã, Portugal: Livros LabCom, 2015. p. 7-42.

REZENDE, Renata; BEDRAN, Laura. Reflexões sobre espaço e comunicação: a transformação da experiência em cotidianos urbanos. LOGOS 43, v. 22, n. 2, p. 18-30, 2015.

\section{RYAN, Marie-Lauren. Narrative as Virtual}

Reality 2: Revisiting Immersion and Interactivity in Literature and Electronic Media. Baltmore: JHU Press, 2015. (v. 2).

SALAVERRÍA, Ramon. Digital Journalism: 25 Years of Research. El professional de la información, v. 28, n. 1, p. 1-25, 2019.

SÁNCHEZ LAWS, Ana Luisa. Can Immersive Journalism Enhance Empathy? Digital Journalism, v. 8, n. 2, p. 1-16, 2017.

\section{SCHUDSON, Michel. The Sociology of News} (Contemporary Sociology). New York: WW Norton \& Company, 2003.

SEIDENGLANZ, René; SPONHOLZ, Liriam. Objetividade e credibilidade midiática: considerações sobre uma suposta relação.

Contemporanea -Revista de Comunicação e Cultura, v. 6, n. 2, p. 1-24, 2009.

SHIN, Dongee; BIOCCA, Frank. Exploring Immersive Experience in Journalism. New Media and Society, v. 19, n. 11, p. 1-24, 2017. SIMS, Norman. Preface. In: SIMS, Norman. Literary Journalism in the Twentieth Century. Illinois, EUA: Northwestern University Press, 2008. p. 1-29.SPONHOLZ, Liriam. Jornalismo, conhecimento e objetividade: além do espelho e das construções. Florianópolis: Insular, 2009.

SUNDAR, Shyam; KANG, Jin; OPREAN, Danielle. Being There in the Midst of the
Story: How Immersive Journalism Affects Our Perceptions and Cognitions. Cyberpsychology, Behavior, and Social Networking, v. 20, n. 11, p. 672-682, nov. 2017.

TAMBOSI, Orlando. Elementos para uma epistemologia do jornalismo. IntercomRevista Brasileira de Ciências da Comunicação, v. 26, n. 2, p. 1-13, 2003.

TEMER, Ana Carolina; SANTOS, Marli. Reportagem em 360 graus: novas formatações da informação na relação televisão e internet. In: CONGRESO LATINOAMERIANO DE INVESTIGADORES EN COMUNICACIÓN, 13., 2016, México. Anais... Cidade do México: ALAIC, 2016

THOMPSON, John. A mídia e a modernidade: uma teoria social da mídia. 5. ed. Petrópolis: Vozes, 1998.

TRENTINI, Bruno. Pour une immersion non transparente. Dans Figures de l'immersion. Cahier ReMix, n. 4, 2014.

TUCHMAN, Gaye. Objectivity as Strategic Ritual: an Examination of Newsmen's Notions of Objectivity. American Journal of Sociology, v. 77, n. 4, p. 660-679, 1972.

VALVERDE, Monclar. Comunicação e experiência estética. In: LEAL, B. S.; GUIMARÃES, C.; MENDONÇA, C. (Ed.). Entre o sensível e o comunicacional. Belo Horizonte: Autêntica, 2010. p. 57-71.

VALVERDE, Monclar. Estética e hermenêutica: a estética da comunicação como hermenêutica do mundo sensivel. In: ENCONTRO ANNUAL DA COMPÓS, 28., 2019, Porto Alegre. Anais... Porto Alegre: Pontifícia Universidade Católica do Rio Grande do Sul, 2019. 
WATSON, Zillah. VR for news: the new reality?

Reuters Institute-Digital News Project 2017.

Disponível em: <https://goo.gl/XMXPAq>.

Acesso em: 25 mar. 2019.

WOLFE, Tom. Radical chique e o novo

jornalismo. São Paulo: Editora Companhia das

Letras, 2005.

\section{Informações sobre 0 artigo}

Resultado de projeto de pesquisa, de dissertação, tese: 0 artigo é um dos resultados da pesquisa que gerou a tese de doutorado de título $A$ imersão como categoria estruturante e indutora de inovações no jornalismo em redes digitais, defendida em 13 de fevereiro de 2020, de Adalton dos Anjos Fonseca, e também do projeto de pesquisa doutoral $A$ experiência em primeira pessoa: a sensação de presença no jornalismo imersivo de Luciellen Lima.

Fontes de financiamento: 0 artigo foi parcialmente financiado por meio de Bolsa CNPq de doutorado recebida pelo autor Adalton dos Anjos Fonseca.

Considerações éticas: Não se aplica.

Declaração de conflito de interesses: Não se aplica.

Apresentação anterior: Uma versão deste artigo foi apresentada no XXVIII Encontro Anual da Compós, 2019, Porto Alegre. Agradecimentos/Contribuições adicionais: Não se aplica. 


\section{A theoretical framework proposal for analysis of experience in immersive journalism}

\section{Abstract}

This article aims to propose a theoretical framework for the analysis of experience in immersive journalism. It starts with the discussion about the relationship between immersion and journalism and the concepts of experience and immersive journalism. The methodology consists of a combination of bibliographic research and product analysis. The theoretical framework proposal is based on four levels: epistemic, strategic, stylistic and aesthetic-that unfold in theoretical and technical aspects. Among the conclusions, these levels show an interrelationship of experiences of agents who share their emotions, repertoires, worldviews and experiences.

\section{Keywords:}

Immersive journalism. Experience. Immersion. Innovation in Journalism.

\section{Adalton dos Anjos Fonseca}

Doutor em Comunicação pelo Programa de Pósgraduação em Comunicação e Cultura Contemporâneas da Universidade Federal da Bahia. Membro do Grupo de Pesquisa em Jornalismo On-line (GJOL). Bolsista CNPq. Universidade Federal da Bahia, Salvador, Bahia, Brasil E-mail: adalton.anjos@gmail.com ORCID: https://orcid.org/0000-0002-5035-0346

\section{Luciellen Lima}

Doutoranda em Comunicação pelo Programa de Pósgraduação em Comunicação e Cultura Contemporâneas da Universidade Federal da Bahia. Participante do Grupo de Pesquisa em Jornalismo On-line-GJOL da UFBA e Pesquisadora do Grupo de Pesquisa em Jornalismo e Mobilidade-MOBJOR da UEPB.

Universidade Federal da Bahia, Salvador, Bahia, Brasil. E-mail: luciellensouzalima@gmail.com ORCID: https://orcid.org/0000-0002-5600-0785

\section{Una propuesta del marco teórico para el análisis de la experiencia de periodismo inmersivo}

\author{
Resumen \\ El artículo tiene como objetivo proponer un \\ marco teórico para el análisis de la experiencia \\ de periodismo inmersivo. Comienza con la \\ discusión sobre la relación entre la inmersión \\ y el periodismo y los conceptos de experiencia \\ y periodismo inmersivo. La metodología \\ consiste en una combinación de investigación \\ bibliográfica y análisis de productos. El marco \\ teórico propuesto se basa en cuatro niveles: \\ epistémico, estratégico, estilístico y estético, que \\ se desarrollan en aspectos teóricos y técnicos. \\ Entre las conclusiones, se indica que estos niveles \\ muestran una interrelación de experiencias \\ de agentes que comparten sus emociones, \\ repertorios, cosmovisiones y experiencias. \\ Palabras clave: \\ Periodismo inmersivo. Experiencia. \\ Inmersión. Innovación en periodismo.
}

\section{Suzana Barbosa}

Doutora em Comunicação pelo Programa de Pósgraduação em Comunicação e Cultura Contemporâneas da Universidade Federal da Bahia. Professora Associada I do Departamento de Comunicação e do Programa de PósGraduação em Comunicação e Cultura Contemporâneas da Faculdade de Comunicação da Universidade Federal da Bahia. Diretora da Faculdade de Comunicação da Universidade Federal da Bahia. Investigadora e coordenadora do Grupo de Pesquisa em Jornalismo On-Line (GJOL).

Universidade Federal da Bahia, Salvador, Bahia, Brasil.

E-mail: suzana.barbosa@gmail.com

ORCID: https://orcid.org/0000-0003-3109-7637

\section{Contribuição dos autores}

Concepção e desenho do estudo: Adalton dos Anjos

Fonseca, Luciellen Lima e Suzana Barbosa.

Aquisição, análise ou interpretação dos dados:

Adalton dos Anjos Fonseca e Luciellen Lima.

Redação do manuscrito: Adalton dos Anjos Fonseca

e Luciellen Lima.

Revisão crítica do conteúdo intelectual: Adalton dos Anjos Fonseca, Luciellen Lima e Suzana Barbosa. 